\title{
Los delitos contra la seguridad y la higiene en el trabajo a propósito del Covid-19*
}

\begin{abstract}
Álvaro Alzina Lozano**
RESUMEN: La protección de la salud de los trabajadores ha aumentado debido al virus Covid-19, provocando numerosas críticas a las administraciones públicas y las empresas por no dotar de suficiente material a sus trabajadores. El Código Penal en sus artículos 316 y 317, recoge la posibilidad de condenar a los responsables de las empresas que no cumplan con las medidas de seguridad $e$ higiene suficientes para evitar el contagio de sus empleados. Esto nos lleva a determinar cuáles son los requisitos necesarios para poder aplicar dicho artículo en sustitución de la sanción administrativa recogida en la Ley de Prevención de Riesgos Laborales.
\end{abstract}

Palabras Clave: Derecho Penal, Derecho de los Trabajadores, Salud, Higiene, Seguridad.

SUMARIO: Introducción. 1. La protección de la salud de los trabajadores. 2. La protección penal de la seguridad e higiene en el trabajo: artículos 316 y 317 del Código Penal. Conclusiones. Fuentes de consulta.

\section{Introducción}

El trabajo como derecho fundamental, aparece recogido en el artículo 35 de la Constitución Española:

Todos los españoles tienen el deber de trabajar y el derecho al trabajo, a la libre elección de profesión u oficio, a la promoción a través del trabajo y a una remuneración suficiente para satisfacer sus necesidades y las de su familia, sin que en ningún caso pueda hacerse discriminación por razón de sexo.

\footnotetext{
* Artículo recibido el 15 de abril de 2020 y aceptado para su publicación el 26 de mayo de 2020.

** Profesor de Derecho Penal, Universidad Rey Juan Carlos. alvaro.alzina@urjc.es
} 
Esto se debe principalmente a la importancia que tiene en la sociedad el desarrollo de una profesión con el fin de poder tener un sustento con el que vivir. Las reglas esenciales del ejercicio del trabajo se establecen en el Estatuto de los Trabajadores.

Los derechos de los trabajadores es una cuestión abordada en todo el continente europeo. La Carta Social Europea, aprobada por el Consejo de Europa en 1961 y ratificada por España en 1978, pone de manifiesto la importancia que tiene en el continente europeo la consideración de los derechos de los trabajadores. Este documento serviría como primer avance en el derecho a unas condiciones de trabajo equitativas, el derecho a poder participar en un sindicato y a la seguridad e higiene en el trabajo, entre otras consideraciones.

Por su parte, la Unión Europea, constituida a través de las Comunidades creadas en 1951 y 1957, acabaría compartiendo el espíritu y voluntad de la Carta Social Europea. El artículo 117 del Tratado de la Comunidad Europea convenía la necesidad de "fomentar la mejora de las condiciones de vida y de trabajo de los trabajadores", sobre todo en la construcción del Mercado Único Europeo, con el fin del desarrollo y la creación del empleo.

En 1989 los Jefes de Estado y de Gobierno reunidos en el Consejo Europeo, presentarían una carta propia que tomaría el nombre de: "Carta Comunitaria de los Derechos Sociales de los Trabajadores" (Anguita Osuna, 2019: 259). Asimismo, se aprobaría la Directiva 89/391/CEE, relativa a la aplicación de las medidas para promover la mejora de la seguridad y de la salud de los trabajadores en el trabajo.

El Tratado de Funcionamiento de la Unión Europea (TFUE) en su Título X -TFUE garantiza una serie de derechos en todos los Estados Miembros, como la aplicación de un principio de igualdad de retribución entre los trabajadores (artículo 157) o la realización de acciones conjuntas relacionadas con las condiciones de trabajo, la higiene en el trabajo y el derecho de sindicación (artículo 156).

Este último artículo se ve refrendado por la Agencia Europea para la Seguridad y la Salud en el Trabajo (EU-OSHA), enfocada a conseguir una mejora en los lugares de trabajo para que sean más seguros, saludables y productivos, en beneficios de todos los agentes sociales (trabajadores, empresarios y las administraciones).

La protección de la seguridad e higiene en el trabajo en España se ve reflejada a través de la normativa laboral y de la protección penal para los casos más graves. En este último ámbito, los delitos contra los derechos de los trabajadores aparecen tipificados en el Título XV del Código Penal (artículos del 311 al 318), en los que se regulan las acciones punibles en el entorno laboral contra los trabajadores. No sólo se castiga a los empresarios o empleadores como personas físicas, sino también las personas jurídicas en su artículo 318:

cuando los hechos previstos en los artículos de este título se atribuyeran a personas jurídicas, se impondrá la pena señalada a los administradores o encargados del servicio que hayan sido responsables de los mismos y a quienes, conociéndolos y pudiendo remediarlo, no hubieran adoptado medidas para ello. En estos supuestos la autoridad judicial podrá decretar, además, alguna o algunas de las medidas previstas en el artículo 129 de este Código.

El Código Penal español protege a los trabajadores que se encuentren en condiciones de inferioridad desde el punto de vista laboral, bien frente a empresarios o empleadores. En el presente artículo se realiza hacer un análisis de cómo es la relación laboral en momentos delicados como el actual, donde es necesaria una especial 
protección de la salud de los trabajadores, más concretamente la que establece en el artículo 316 y 317.

La definición de trabajador aparece en el Estatuto de los Trabajadores: "la persona que voluntariamente presta sus servicios retribuidos por cuenta ajena y dentro del ámbito de organización y dirección de otra persona, física o jurídica denominada empleador o empresario". Del mismo modo, es importante precisar el concepto de empresario, que aparece seguidamente del concepto de trabajador en el mismo Estatuto:

serán empresarios todas las personas, físicas o jurídicas, o comunidades de bienes que reciban la prestación de servicios de las personas referidas en el apartado anterior, así como de las personas contratadas para ser cedidas a empresas usuarias por empresas de trabajo temporal legalmente constituidas. (Art 40, ET)

Estos son los dos sujetos principales que, junto con la administración, deben asegurar unas buenas condiciones de trabajo. Debemos tener en cuenta la seguridad y la higiene de los trabajadores es importante para evitar que enfermedades o virus como el Covid19 , se pueda transmitir o incluso infectar en su puesto de trabajo pues este tipo de situaciones pueden evitarse.

Este virus es considerado pandemia por la Organización Mundial de la Salud, está afectando a un gran número de individuos a lo largo de todos los continentes. Debemos reflexionar si desde el ámbito laboral español se protege la salud de los trabajadores que están en primera línea de batalla (personal sanitario, cuerpos y fuerzas de seguridad del Estado, personal de limpieza, personal de supermercado...). Estos trabajadores se exponen de manera constante durante su jornada laboral y, a pesar de existir obligación de cumplir el precepto anterior (seguridad en el trabajo), han aparecido noticias en los medios de comunicación de la queja por parte de los profesionales tanto sanitarios como de otros ámbitos por la falta de equipamiento para evitar el posible contagio.

La declaración del Estado de Alarma por parte del gobierno español ha provocado que la mayoría de las empresas y administraciones públicas continúen su actividad con sus empleados desde casa a través de medios telemáticos, pero hay determinados puestos de trabajo, como los grupos que hemos señalado anteriormente, que no pueden acogerse a este régimen. Así, tanto el empresario como la Administración pública deben asegurar la seguridad y la higiene de sus trabajadores.

\section{La protección de la salud de los trabajadores}

Al igual que la Constitución protege el derecho al trabajo en el artículo 35, también recoge la salud de los trabajadores en el artículo 40.2, y que por lo tanto, las Administraciones deben velar porque este precepto se cumpla:

Asimismo, los poderes públicos fomentarán una política que garantice la formación y readaptación profesionales; velarán por la seguridad e higiene en el trabajo y garantizarán el descanso necesario, mediante la limitación de la jornada laboral, las vacaciones periódicas retribuidas y la promoción de centros adecuados. (Art $40 \mathrm{CE}$ )

La protección de la salud de los trabajadores es uno de los ejes fundamentales en la lucha por los derechos de los trabajadores. La implicación de todos los agentes sociales (empresas, Estado y trabajadores) es necesario para llegar a un consenso en la importancia que tiene dotar a los empleados de medios suficientes para poder realizar su función de manera segura. 
El concepto de salud e higiene en el trabajo es definido de manera acertada por Arroyo Zapatero como "la ausencia de riesgos para la vida y la salud del trabajador dimanante de las condiciones materiales de prestación del trabajo" (Arroyo Zapatero, 1998: 1507). Es por ello que, aunque la formación es importante (cursos de prevención de riesgos laborales, o manejo de productos químicos), lo principal es la correcta utilización del material de protección, cuestión fundamental para evitar contagios.

De esta cuestión podemos traer en a colación una valoración expuesta por Cárcoba sobre la salud en el trabajo, en la que determina que uno de los principios fundamentales es la supresión de cualquier daño a la salud derivado de las condiciones que hay en el mismo, por lo que se tiene que considerar como innecesario, es decir, se puede prevenir (Cárcoba, 1996: 464).

Una gran parte de los contagios que ha habido durante el Estado de Alarma donde la mayoría de las personas han tenido muy limitada la movilidad, han sido de trabajadores durante el desarrollo de su actividad laboral debida, principalmente, a la falta de equipos y material suficiente para poder realizar el trabajo de manera segura. No sólo nos referimos al personal sanitario, que ha sido el más perjudicado, sino también al personal de limpieza y servicios y policías y militares que están colaborando en la organización logística y sanitaria.

La falta del material para poder hacer frente al virus, afecta principalmente a la seguridad de los trabajadores, provocado principalmente por la dejadez y la falta de previsión frente a este tipo de sucesos, pues se ha valorado más la mejora de la producción y los beneficios, pues el fin ha sido hacer las empresas más rentables y las Administraciones públicas más eficientes. En este sentido, Zúñiga alude a la producción postfordista en la que se subcontratan la producción a otras empresas o a trabajadores autónomos con el fin de reducir costes y así evitar tener que trabajar por la protección de sus propios trabajadores, lo que provoca una mejora de sus beneficios al no tener que invertir en seguridad, asimismo, considera que las normas económicas, políticas y laborales, apoyarían esta transformación suprimiendo los derechos laborales esenciales de los trabajadores (Zúñiga, 2008: 10).

Estas críticas han surgido a lo largo del tiempo desde distintos ámbitos, pero sobre todo, desde el ámbito sindical. En palabras de Ramírez Barbosa, está inobservancia de la obligación genérica de seguridad y salud en el trabajo debe atajarse, pues viene establecido en la normativa laboral como uno de los deberes que conforman las responsabilidades en materia de prevención de riesgos laborales, así como planes de prevención de riesgos laborales, formación, observancia y vigilancia (Ramírez, 2007: 141).

Con el propósito de asegurar el cumplimiento de todas las medidas de seguridad e higiene en el trabajo, se aprobaría la Ley de Prevención de Riesgos Laborales (Ley 31/1995), con el propósito principal de armonizar nuestras leyes laborales al acervo comunitario, pero además con el fin de reconocer la salud en el ámbito del trabajo y establecer unos criterios de protección específicos. Pues como señala la propia Ley en su exposición de motivos:

La protección del trabajador frente a los riesgos laborales exige una actuación en la empresa que desborda el mero cumplimiento formal de un conjunto predeterminado, más o menos amplio, de deberes y obligaciones empresariales y, más aún, la simple corrección a posteriori de situaciones de riesgo ya manifestadas. La planificación de la prevención desde el momento mismo del diseño del proyecto empresarial, la evaluación inicial de los riesgos inherentes al trabajo y su actualización 
periódica a medida que se alteren las circunstancias, la ordenación de un conjunto coherente y globalizador de medidas de acción preventiva adecuadas a la naturaleza de los riesgos detectados.

Un ejemplo del riesgo que supone desempeñar determinados puestos de trabajo lo pone de manifiesto el Tribunal Supremo en una sentencia de 2013, en la que señala como el trabajador se encontró en una situación de incapacidad temporal derivada de enfermedad profesional, pues la patología que le había sido diagnosticada tenía un nexo existente con los productos químicos que utilizaba en el desempeño de su puesto de trabajo (STS 4403/2013).

Este cuidado objetivo que debe disponer el empresario, ha sido reforzada en la propia norma en el artículo 42.1 de la Ley, al establecer la imposición de sanciones a los empresarios que incumplan las condiciones impuestas:

El incumplimiento por los empresarios de sus obligaciones en materia de prevención de riesgos laborales dará lugar a responsabilidades administrativas, así como, en su caso, a responsabilidades penales y a las civiles por los daños y perjuicios que puedan derivarse de dicho incumplimiento. (Art 42.1 LPR)

Para la imposición de estas sanciones debe haber una infracción previa por parte del empresario, lo que nos lleva al planteamiento de las conductas que son objeto de infracción debemos acudir al Real Decreto Legislativo 5/2000, de 4 de agosto, en el que se establecen cuáles son los tipos de infracción que son motivo de sanción.

Esta razón ha sido la principal la cual ha llevado al legislador a establecer un proceso de leyes administrativas con el propósito de sancionar las conductas contrarias a los derechos de los trabajadores, valorándose la gravedad de cada situación para determinar si es infracción muy grave, grave o leve. En los casos en los que se ha considerado que puede en poner en peligro la vida o la integridad física del propio trabajador se ha establecido la intervención del Derecho penal. Aunque no podemos olvidar el principio de última ratio, que sirve como freno a la utilización excesiva del Derecho penal, pues no podemos olvidar que la pena debe ser el último recurso.

Esta falta de la atención debida a los riesgos por parte de empresario, ha provocado que el legislador haya tenido que adelantar las barreras punitivas y hacer partícipe al Derecho penal, pues como señala Gallardo García: "la multa pecuniaria es la pena reina de la vía administrativo laboral, y ésta, no consigue los niveles de motivación necesarios para que el empresario deje de poner en peligro la vida y la salud de sus empleados" (Gallardo, 2006: 270).

\section{La protección penal de la seguridad e higiene en el trabajo: artículos 316 y 317 del código penal}

La expansión del Derecho penal hacia todos los ámbitos y sectores de la sociedad es un fenómeno que ha sido abordado por la jurisprudencia y la doctrina durante estos años (Silva Sánchez: 2011; Berdugo Gómez de la Torre; 2012). En el ámbito que compete a este trabajo encontramos sentencias como la de la Audiencia provincial de Lérida en la que se alude a la fuerza expansiva del Derecho penal, considerando que no todas las cuestiones administrativas/laborales relacionadas con las medidas de seguridad y la higiene en el trabajo deben pasar el umbral de la sanción laboral para llegar a ser una condena penal, sino que la implicación del propio Código Penal en este ámbito se deberá ser cuando: 
el riesgo suponga un peligro potencial para la vida, salud e integridad física, fuera conocido o cognoscible por quien tenía la obligación de garantizarlos y que en atención a las demás circunstancias, la omisión para evitar la producción del riesgo impliquen intencionalidad en la omisión o infracción del deber de cuidado. (Audiencia Provincial de Lérida 271/2009)

En este sentido, Terradillos Basoco hace una valoración respecto a la utilización de los instrumentos penales para la tutela de la vida y la salud de los trabajadores, expresando que debe utilizarse por el bien jurídico que se ve atacado por el ataque que se ha infringido. Asimismo, el autor observa como beneficio posible de la imposición de una pena la "función didáctica", al manifestar este hecho la importancia que tiene la protección de los trabajadores: "integrándolos en el catálogo de bienes jurídicos de primer orden, de irrenunciable protección pública” (Terradillos Basoco, 2006: 18-26).

Del mismo modo Pérez Ferrer alude al principio de intervención mínima del Derecho penal, para los casos que infrinjan la normativa de prevención de riesgos laborales creando un peligro grave, siempre y cuando tenga la misma terminología que el descrito en el artículo 316 (Pérez Ferrer, 2016: 147). Por tanto, no toda infracción de la norma laboral debe ser considerada delito sino sólo aquellas que puedan poner en peligro la salud de los trabajadores.

Otro de los motivos por el que se ha optado por el Derecho penal es por la necesidad de seguir protegiendo este ámbito, pues como señala Martínez Barroso:

el fracaso de muchas de las políticas preventivas o la obtención de resultados por debajo de lo deseado, como demuestra el elevado índice de siniestralidad laboral y la falta de consecución de los niveles de seguridad buscados, hace en ocasiones necesario acudir al Derecho Penal. (Martínez Barroso, 2016: 36-45)

Este adelanto de la barrera punitiva llevaría al legislador a plantear dentro del Título del Código Penal referido a los derechos de los trabajadores, dos artículos sobre la seguridad y la higiene en el trabajo (Salvador Concepción, 2011: 742), el primero de ellos en su forma dolosa en el artículo 316:

los que con infracción de las normas de prevención de riesgos laborales y estando legalmente obligados, no faciliten los medios necesarios para que los trabajadores desempeñen su actividad con las medidas de seguridad e higiene adecuadas, de forma que pongan así en peligro grave su vida, salud o integridad física, serán castigados con las penas de prisión de seis meses a tres años y multa de seis a doce meses. (Art 316, CP)

Y el segundo en su forma imprudente en el artículo 317: "cuando el delito a que se refiere el artículo anterior se cometa por imprudencia grave, será castigado con la pena inferior en grado".

Recapitulando ideas, debemos apoyar la reflexión de Lascuráin respecto a la utilización del Derecho penal para las conductas más graves en este ámbito, pues presenta unos argumentos sólidos respecto a la criminalización de las conductas empresariales irregulares en el ámbito de las relaciones laborales, al considerarse ilegítima desde la perspectiva del Derecho Penal y del propio de un Estado democrático, por llegar a poder existir sanciones desproporcionadas en relación con hechos de desvalor leve, pudiendo provocar un "severo nocivo efecto disuasorio general de la actividad productiva, con todo lo que ello comporta para el desarrollo económico" (Lascuraín Sánchez, 2004: 20).

En consecuencia, es necesario garantizar unas condiciones de seguridad en el trabajo dignas, así como evitar una siniestralidad alta en el entorno laboral, que en 
determinadas ocasiones ocurre por no tomar las medidas de seguridad exigidas. Es un tipo penal omisivo pues protege la ausencia de riesgo para la vida o para salud en la realización de un trabajo. Este derecho debe ser asegurado por el empresario o empleador (sujetos activos) siendo el trabajador el sujeto pasivo.

Esta referencia respecto al tipo omisivo también la encontramos en la Sentencia del Tribunal Supremo 1355/2000, al referirse al artículo 316 como un tipo complejo, que cuenta con dos elementos principales, tal y como define el propio tipo penal: el primero de ellos es la omisión realizada por parte del empresario que provoca una infracción de las normas de prevención de riesgos laborales; y la segunda, la consecución de un peligro grave para la vida, la salud o la integridad física (Tribunal Supremo 6307/2000).

El peligro real y grave que señala la Sentencia aparece definido en la Ley 31/1995 de Prevención de Riesgos Laborales en su artículo 4.4: "Se entenderá como «riesgo laboral grave e inminente» aquel que resulte probable racionalmente que se materialice en un futuro inmediato y pueda suponer un daño grave para la salud de los trabajadores". Igualmente, en el artículo 21 aparecen las actuaciones que el empresario está obligado a realizar cuando un trabajador puede sufrir un peligro grave e inminente.

Por tanto, lo que pretender castigar el legislador con este precepto penal es la no facilitación de los medios para evitar esta puesta en peligro del trabajador, que en ocasiones puede llevar incluso a que el trabajador acabe falleciendo, como en los casos de sanitarios que están siendo contagiados en los propios hospitales al tratar a enfermos del Covid-19 con el material insuficiente para poder evitar contagios.

El artículo 316 que como ya hemos afirmado se configura como un medio omisivo que pretende proteger la seguridad y la higiene, la cual es entendida por la Audiencia Provincial de Zaragoza como una ausencia de riesgo para el trabajador de lo que el Estado debido a la protección constitucional del 40.2 tiene obligación de velar por ella. Por lo tanto, estaríamos hablando que para que exista la conducta típica debe haberse omitido este principio, es decir, la obligación en materia de seguridad de los trabajadores que el ordenamiento impone a los sujetos activos (Audiencia Provincial Zaragoza 504/2019).

Esta afirmación de la Audiencia Provincial nos hace señalar que el artículo 316 y 317 nos remiten a una serie de normas sobre prevención de riesgos laborales, lo que nos lleva a considerar que se trata de una norma penal en blanco. Por ello los empresarios y los responsables de los departamentos de prevención de riesgos laborales que en este delito actúan como sujetos activos, son garantes de que se cumplan estas normas:

pero no es cualquier infracción de la normativa laboral, sino que esa norma infringida debe poner en peligro grave la vida, salud, o integridad física, es decir debe tratarse de una infracción muy grave, y cuya omisión sea capaz de generar aquel riesgo grave, existiendo un adecuado nexo de causalidad. (Audiencia provincial de Cádiz 668/2011)

Que sea una infracción de peligro grave para la salud es el fundamento para entender que hemos superado la barrera de la sanción administrativa laboral y debemos acudir a la normativa penal. Este riesgo grave es el principal fundamento en el que se basa el principio de intervención mínima del derecho penal, que impide traspasar los límites propios del ámbito puramente laboral por lo que se sancionaría únicamente desde el ámbito administrativo (Audiencia Provincial Zaragoza 504/2019).

Es por ello que debemos fijar la atención en la Ley de Prevención de Riesgos Laborales, con el fin de conocer que elementos son de cumplimiento por parte del 
empresario. Uno de los elementos principales que aparece en dicha Ley es la definición que aporta sobre el riesgo grave e inminente, pues el empresario que pueda percibir esta circunstancia tiene que cumplir una serie de obligaciones para no tener sanción administrativa y si el riesgo excede la vía administrativa pues pone en peligro la salud de los trabajadores la condena penal:

a) Informar lo antes posible a todos los trabajadores afectados acerca de la existencia de dicho riesgo y de las medidas adoptadas o que, en su caso, deban adoptarse en materia de protección; b) Adoptar las medidas y dar las instrucciones necesarias para que, en caso de peligro grave, inminente e inevitable, los trabajadores puedan interrumpir su actividad y, si fuera necesario, abandonar de inmediato el lugar de trabajo. En este supuesto no podrá exigirse a los trabajadores que reanuden su actividad mientras persista el peligro, salvo excepción debidamente justificada por razones de seguridad y determinada reglamentariamente. c) Disponer lo necesario para que el trabajador que no pudiera ponerse en contacto con su superior jerárquico, ante una situación de peligro grave e inminente para su seguridad, la de otros trabajadores o la de terceros a la empresa, esté en condiciones, habida cuenta de sus conocimientos y de los medios técnicos puestos a su disposición, de adoptar las medidas necesarias para evitar las consecuencias de dicho peligro.

Respecto a la protección de los trabajadores frente al Covid-19, podemos tomar como ejemplo la sentencia de la Audiencia Provincial de Madrid de 2012, en la que señalaría que la conducta típica del artículo 316 sería la negativa a facilitar "el equipamiento personal (cascos, mascarillas, anclajes, etcétera) y colectivo (mecanismos de seguridad en la maquinaria, sistemas de protección mediante cercado de huecos o colocación de redes en prevención de caídas, y otros semejantes)". Además de una serie de obligaciones que tienen relación con el deber de la empresa de dotar del material suficiente para proteger la salud, la vida y la integridad del trabajador, después de haber evaluado los riesgos y haber planificado correctamente qué equipos y que formación necesitan los trabajadores para desempeñar su trabajo, por lo que finaliza la Audiencia estableciendo que: "Ios medios negados a los trabajadores han de ser los necesarios para que éstos desempeñen su actividad con las medidas de seguridad e higiene adecuadas" (Audiencia Provincial de Madrid 1418/2012).

Serrano Piedecasas considera que respecto a los medios que se refiere son las medidas consistentes en la formación, la adecuación entre su capacidad y las tareas encomendadas, la adopción de medidas de emergencia o el derecho a la coordinación de las actividades preventivas (Serrano Piedecasas, 2002: 100).

Por tanto, en este tipo penal es fundamental que afecte a la vida y a la salud de los trabajadores (Gallardo García, 2006: 271). Pero además, es importante determinar si este deber recae en el propio empresario o se debe a una "conducta imprudente del trabajador al incumplir las diferentes obligaciones que en la materia le impone también el ordenamiento jurídico laboral en el artículo 29 de la Ley de Prevención de Riesgos Laborales" (Martínez Barroso, 2016: 36-45).

Respecto al bien jurídico, Serrano Piedecasas considera que la protección es la seguridad en el trabajo, con el fin de equilibrar la desigualdad material del trabajador asalariado, con el fin de proteger su campo de actividades (Serrano Piedecasas, 2002: 98). Además, la Audiencia Provincial de Lérida resalta que es un bien jurídico colectivo, un derecho mínimo del trabajador nacido de la relación laboral con el que se procura la seguridad de un grupo social integrado por las personas que prestan servicios retribuidos por cuenta ajena (Audiencia Provincial de Lérida 271/2009). 
En estos días, desgraciadamente, se han dado casos de fuerzas y cuerpos de seguridad del Estado, y de personal sanitario que ha fallecido a causa del Covid-19 en el ejercicio de sus funciones. Según el tipo penal debemos concretar qué responsabilidad ha tenido el empleador, en este caso la Administración pública, al ser garante del deber de vigilancia para que los trabajadores puedan tener los equipos suficientes para poder hacer su trabajo sin poner en peligro su salud, habiendo planificado un posible riesgo sanitario. Haciendo alusión al artículo 17 de la Ley de Prevención de riesgos laborales, el empresario adoptará las medidas necesarias con el fin de que los equipos de trabajo sean adecuados para el trabajo que deba realizarse y convenientemente adaptados a tal efecto, de forma que garanticen la seguridad y la salud de los trabajadores al utilizarlos.

Del mismo modo, para poder considerar responsable a la Administración debemos aludir a lo que plantea Olaizola Nogales, al referirse que debe tenerse en cuenta la previsibilidad de la lesión, es decir, plantear la teoría del hombre medio ideal, para constatar si la conducta realizada ha sido peligrosa. En concreto, podríamos señalar que ningún hospital está preparado para recibir tan avalancha de pacientes en estado grave, pues como se ha podido observar en otros países, todos han tenido que improvisar nuevos hospitales $y$ han tenido problemas para abastecer a su personal del equipamiento suficiente para que puedan estar a salvo del virus. Por lo que podríamos considerar que este elemento no se cumpliría, aunque la autora señala que se puede tener responsabilidad penal siempre y cuando: "la conducta es objetivamente igual de grave tanto si el sujeto conoce que está infringiendo una norma de cuidado o no lo conoce, pero debería conocerlo" (Olaizola Nogales, 2010; 8-9).

De acuerdo con el tipo penal, el sujeto activo, en este caso, será el responsable de dotar de los medios necesarios a los trabajadores para que desempeñen su actividad sin poner en riesgo su salud (Ramírez Barbosa, 2007:140). Esto nos remitirá a analizar la responsabilidad del empresario y sus posibles delegaciones a los responsables de prevención de riesgos laborales de las empresas o de las Administraciones Públicas (Martínez Barroso, 2016: 36-45). Es por ello que señala la autora que el sujeto activo en este delito es muy amplio, el empresario como persona que ostenta el poder de dirección, así como puede ser también los técnicos en prevención de riesgos laborales cuando se haya delegado tal competencia sobre ellos.

Siguiendo a Lascuraín debemos afirmar que el titular de la empresa es el responsable, aunque este haya delegado frente al responsable de prevención, pues la misión del empresario es la observancia de que se cumplen las normas, siempre y cuando el que recibe la delegación haya aceptado dicha encomienda. Igualmente, ocurriría en el caso de los contratistas si el contrato es una delegación de funciones y no una prestación de servicios (Lascuraín Sánchez, 2006: 62).

Para conocer quiénes son los obligados en materia de seguridad en el trabajo, debemos acudir a la Ley de Prevención de Riesgos laborales, más concretamente al artículo 14.2:

En cumplimiento del deber de protección, el empresario deberá garantizar la seguridad y la salud de los trabajadores a su servicio en todos los aspectos relacionados con el trabajo. A estos efectos, en el marco de sus responsabilidades, el empresario realizará la prevención de los riesgos laborales mediante la integración de la actividad preventiva en la empresa y la adopción de cuantas medidas sean necesarias para la protección de la seguridad y la salud de los trabajadores, con las especialidades que se recogen en los artículos siguientes en materia de plan de prevención de riesgos laborales, evaluación de riesgos, información, consulta y participación y formación de los trabajadores, actuación en casos de emergencia y de riesgo grave e inminente, vigilancia de la 
salud, y mediante la constitución de una organización y de los medios necesarios en los términos establecidos en el capítulo IV de esta ley. (Art 14.2 LPR)

En este artículo señala como obligación del empresario dotar a los trabajadores de la seguridad suficiente para poder desempeñar su trabajo, así como de formar equipos de prevención de riesgos laborales para asegurar el cumplimiento de la Ley, por lo que encontramos como posibles sujetos activos ambos grupos, pero siempre y cuando como señala Lascuraín haya aceptado el equipo de prevención dicha función.

En definitiva, el objeto principal que se persigue es conocer quién es el sujeto activo obligado legalmente a asegurar la salud en el trabajo, señalando Zúñiga que principalmente este tipo va destinado al empresario, pues como beneficiario de la actividad productiva de la empresa, es el "titular para adoptar las medidas preventivas pertinentes, sino también para hacer cumplir y vigilar el cumplimiento de las normas de seguridad e higiene dentro de la empresa" (Zúñiga Rodríguez, 2008: 5).

Respecto al sujeto pasivo hay un acuerdo en que puede ser cualquier trabajador, en el que recae la puesta en peligro, pues en estos casos la salud, por ejemplo, del familiar del trabajador que puede caer contagiado por este mismo no tiene repercusión penal para aplicar el tipo penal, pues el propio Título define que es una protección de los trabajadores en el desarrollo de su trabajo y por lo tanto, el empresario tiene que tener una especial atención para que no sufra ningún daño predecible y evitable.

Por último, respecto a la parte subjetiva del tipo debemos mencionar que se trata el artículo 316 de un tipo doloso, pues el autor es consciente del riesgo grave que pueden asumir los trabajadores, y con su falta de acción, es decir, su omisión de realizar alguna actividad para evitarlo es lo que constituye el dolo. De esta forma la Audiencia Provincial de Zaragoza se ha referido a que lo que pretende perseguir el tipo penal es "la conciencia de la infracción de las normas de prevención y el conocimiento de la ausencia de facilitación de los elementos de seguridad que se precisan en la ejecución del trabajo". Precisamente considera suficiente el dolo eventual, manifestado en la posibilidad alta de que se estén infringiendo normas de prevención de riesgos laborales, que pueda materializarse en un resultado (Audiencia Provincial Zaragoza 504/2019). Asimismo, la Audiencia Provincial de Baleares matiza que para entender la voluntad dolosa del empresario hay que conocer a sabiendas el peligro que supone de manifiesto la voluntad dolosa (Audiencia Provincial de Baleares 223/2014).

Por otra parte, podríamos analizar si el comportamiento de las autoridades puede estar más relacionadas con el artículo 317, es decir, en su forma imprudente (Muñoz Conde: 2015: 362). Este artículo conlleva una pena inferior en grado a la establecida en el tipo doloso, basada en la puesta en peligro grave de los trabajadores, en la que el empresario no ha actuado de manera cuidadosa. En este sentido, aunque la puesta en peligro de la salud de los trabajadores se ha puesto en peligro por encima de lo permitido, pero se han ido tomando las medidas necesarias para evitarlo.

Finalmente, cabe destacar que dentro de la imprudencia, no queda delimitado de manera certera la imprudencia grave o leve, por lo que presenta Martínez Barroso que esta falta de delimitación es no facilita para fijar el criterio de cuando la conducta podrá ser relevante penalmente o si por el contrario, se deberá acudir a la norma laboral (Martínez Barroso, 2016: 36-45). 


\section{Conclusiones}

La crisis del coronavirus o Covid-19, ha desatado numerosas cuestiones referidas a la salud y a la protección de la seguridad de los trabajadores. Muchas empresas para preservar la salud, siempre y cuando su función empresarial lo permitía, han permitidos que sus empleados trabajasen desde sus propias casas. Pero hay un gran número de trabajadores que por su tipo de profesión han tenido que seguir acudiendo a sus puestos de trabajo.

Es por ello, que se ha puesto de manifiesto una mejora de las condiciones de seguridad para evitar los contagios, objeto principal de las principales reclamaciones de los trabajadores, pues en ocasiones se han estado contagiando también, siendo más de 10.000 los sanitarios que tienen la enfermedad.

Para paliar este tipo de situaciones, en las que no tienen los suficientes recursos, siempre y cuando no haya sido por negligencia o intencionadamente por el empresario o por la Administración, el legislador incluiría como la salud y la higiene en el trabajo como uno de los aspectos a proteger, tanto desde el Derecho Administrativo como en los casos más graves desde el Código Penal.

El delito aparece tipificado en el artículo 316 en su comisión dolosa y en el 317 en la forma imprudente, y viene a presentar un tipo omisivo concreto que basta solo con la falta de acción del empresario para poder tener repercusiones penales, siempre y cuando se ponga en riesgo de manera grave la salud de sus trabajadores.

Finalmente, debemos señalar que en los momentos que vivimos no estaría contemplado por ahora la utilización de este tipo penal, pues la administración y las empresas han dotado dentro de las posibilidades que existen del material y de la formación suficiente para seguir evitando que pueda haber más contagios, pues los contagios que hemos expuesto anteriormente, se debían a la falta de material, pero no podemos considerar que haya habido una negligencia, al no esperarse de ningún modo que pudiese haber una pandemia a nivel mundial, pero esto puede servir para recapacitar a las autoridades con el fin de dotar de más recursos y de mayor previsión para futuras epidemias. 


\section{Fuentes de consulta}

Anguita Osuna, J.E. (2019). Marco histórico jurídico de la acción social en la Unión Europea. Medidas contra la pobreza y la exclusión social. Revista Aequitas, número 14.

Arroyo Zapatero, L. (1998). Manual de Derecho del Trabajo, Barcelona. AA.VV. Comentarios al nuevo Código Penal, Quintero Olivares, G. (Dir.).

Berdugo Gómez De La Torre, I. (2012). Viejo y nuevo Derecho penal. Principios y desafíos del Derecho penal de hoy. Madrid. Iustel.

Cárcoba, Á. C. (1996). Salud laboral y Ley de prevención de riesgos laborales. Rev Esp Salud Pública, vol. 70, no 4.

Gallardo García, R. M. (2006). La protección penal de la salud de los trabajadores. DS: Derecho y salud, vol. 14, no 2.

Lascuraín Sánchez, J. A. (2006). La imputación penal del accidente de trabajo. Tutela penal de la seguridad en el trabajo. Universidad de Deusto.

Lascuraín Sánchez, J. A. (2004). Los delitos contra los derechos de los trabajadores: lo que sobra y lo que falta. Anuario de derecho y ciencias penales, vol. 57, no 1.

Martínez Barroso, Ma R. (2016). Sujetos responsables de los incumplimientos en materia preventiva. Albacete, Bomarzo.

Muñoz Conde, F. (2015). Manual de Derecho penal parte especial. Valencia, Tirant Lo Blanch.

Olaizola Nogales, I. (2010). Delitos contra los derechos de los trabajadores (arts. 316 y 317 CP) y su relación con los resultados lesivos. InDret, no 2.

Ramírez Barbosa, P. A. (2007). Determinación de la conducta típica como elemento objetivo del tipo de delito contra la seguridad y salud en el trabajo. Revista penal, no 19.

Salvador Concepción, R. (2012). Antecedentes del actual delito de creación de riesgo para la salud del trabajador. Revista de Derecho de la UNED (RDUNED), no 11.

Serrano Piedecasas, J. R. (2002). La responsabilidad penal del empresario, personal técnico y de los servicios de prevención en los delitos contra la seguridad e higiene en el trabajo. Revista penal, no 10. 
Silva Sánchez, J. M. (2011). La expansión del Derecho penal. Aspectos de la política criminal en las sociedades postindustriales. Buenos Aires, Edisofer.

Terradillos Basoco, J. M. (2006) Respuesta penal frente a la siniestralidad laboral. Cuadernos Penales José María Lídon, Bilbao, vol. 3.

Zúñiga Rodríguez, L. (2008). Problemas de responsabilidad (penal, administrativa y civil) en el ámbito empresarial por accidentes de trabajo. Revista Electrónica de Ciencia Penal y Criminología, no 10-10.

\section{Legisgrafía}

Tribunal Supremo - Sala Cuarta, de lo Social STS, 12 de Julio de 2013, № de Recurso: 2294/2012. Roj: STS 4403/2013.

Tribunal Supremo, Sala de lo Penal. № de Recurso: 4716/1998. Roj: STS 6307/2000

Audiencia Provincial de Lérida, № de Recurso: 178/2008. Roj: SAP L 271/2009.

Audiencia Provincial de Baleares, № de Recurso: 223/2014.

Audiencia Provincial Zaragoza, № de Recurso: 1051/2018, Roj: SAP Z 504/2019

Audiencia Provincial de Madrid, № de Recurso: 1418/2012

Audiencia provincial de Cádiz, № de Recurso: 135/2010. Roj: SAP CA 668/2011 